\title{
PRESENT STATE OF STATISTICS FROM HOSPITAL IN-PATIENT DATA AND THEIR USES
}

\author{
J. S. A. ASHLEY
}

Organisation of Medical Care Unit, Department of Public Health, London School of Hygiene and Tropical Medicine

Monitoring the performance of health services has now become official policy (Department of Health and Social Security, 1971). At present hospital management has available to it the largest body of data of any part of the total health system. The Hospital In-Patient Enquiry, the Annual Hospital Returns, and Hospital Activity Analysis all can and do contribute in this respect. But is it possible for these three interdependent sources to serve the varying and often competing needs of administrators, accountants, medical 'cogwheel' (Ministry of Health, 1967) managers, and clinicians? Equally, although they are a source of valuable research information are they exploited enough?

A review of these three sources is therefore opportune in order to consider the aims and objects of each and the extent to which these have been achieved, to examine their accuracy, other uses, and limitations, and to assess the needs for changes or additions to the data or their presentation to meet the needs for the future.

\section{The Hospital In-Patient EnQuiRy}

On 1 January, 1949 the first in-patient summaries for a national morbidity enquiry were completed in 85 hospitals in England and Wales, and so the Hospital In-Patient Enquiry (HIPE) was born. At first its scope was modest and data collection was confined to a small number of volunteer hospitals, of which teaching hospitals formed the majority. In the early years summaries were supplied on all cases 'discharged', but since 1952, with the gradual expansion of the enquiry to include all non-psychiatric hospitals, data have been obtained only on a systematic $10 \%$ sample of discharges. Since 1958 all hospitals eligible have been required to supply information and virtually total coverage has been achieved.

Reports from HIPE are produced annually but with the complexities of data collection, analysis, and publication the volumes have usually been issued two or more years after the year to which they refer. Thus, currently, the latest report in full published form is that of 1968 (Department of
Health and Social Security and Office of Population, Censuses and Surveys, 1972a), but a preliminary report for 1969 has already been issued (Department of Health and Social Security and Office of Population, Censuses and Surveys, 1972b); and data for 1970 are available for use by research workers. In consequence, comparisons of hospital-treated diseases are now possible across more than two decades.

\section{HIPE as a Source of Morbidity Data}

HIPE was conceived primarily as a source of information about morbidity but it is self-evident that illness managed in hospitals is, for the majority of diseases, a selected fraction (Morris, 1957; World Health Organisation, 1968) the dimensions of which are governed by a variety of factors (Uemura, 1970). For a few conditions, however, and in the initial report appendicitis was specified as an example (MacKay, 1951), hospital admissions can measure virtually total morbidity. However, HIPE was expected to be of more value from its ability to compare morbidity, for example between age groups or geographical areas, over a much wider spectrum of conditions. Halevi (1969), for instance, compared the patterns of hospitalization for 18 conditions between England and Wales, using HIPE data, and similarly obtained data for Israel.

To illustrate both these concepts Table I shows the admission rates for appendicitis for the different hospital regions during three recent years (1967-69). These demonstrate a persistently wide range around the national rate, the highest rate being in the region of $50 \%$ higher than the lowest. Although individual regions have varied in their position, Manchester and Wales have consistently had some of the highest rates and Wessex and Sheffield some of the lowest. That the appendix is removed during most such admissions is confirmed by the regional rates for this operation which roughly follow the same trend. Even greater variations of appendectomy rates have recently been demonstrated in Germany, between city districts (Lichtner and Pflanz, 1971), but in contrast to the ease with 
TABLE I

APPENDICITIS IN ENGLAND AND WALES, MALE AND FEMALE

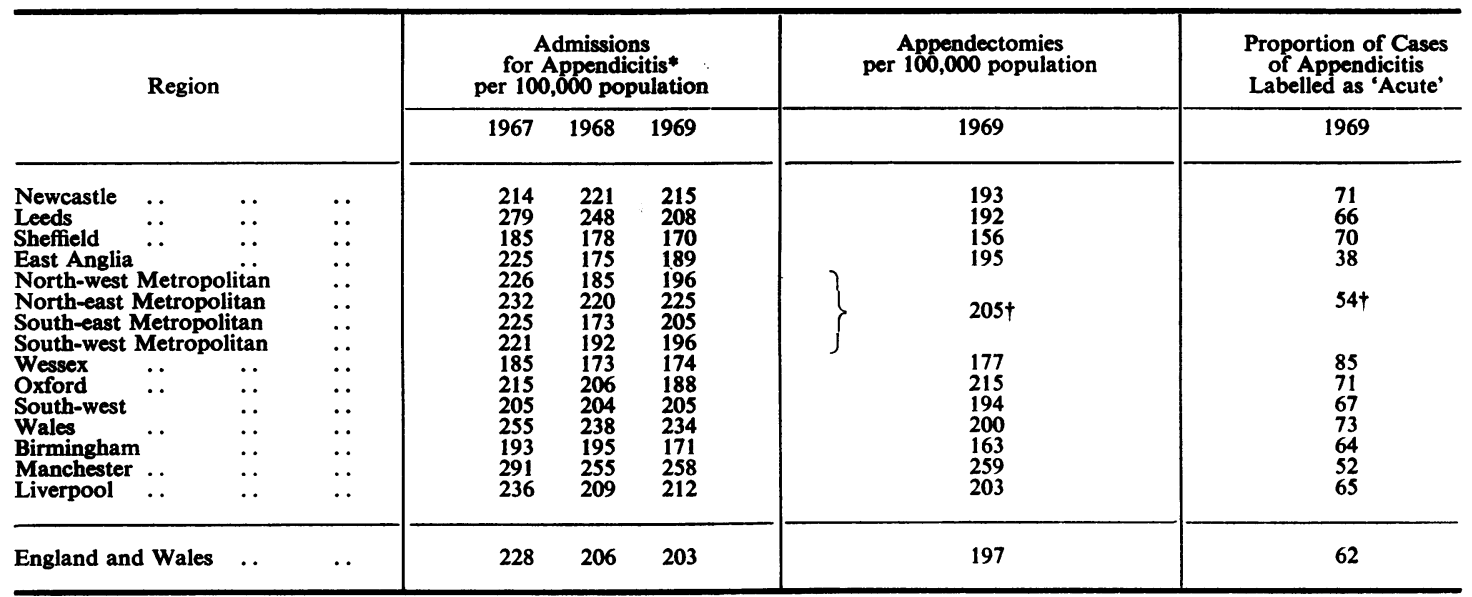

* Including (except for 1967) a small number of 'other diseases of the appendix'.

+ All Metropolitan regions combined.

Source: HIPE (published and unpublished data)

which British data can be obtained, this required the laborious extraction of over 6,000 case records.

Wide differences in the proportions of cases labelled as 'acute' raise doubts as to the number of 'normal' organs removed, the admissions for which will artificially inflate the total morbidity of true appendicitis (Lee, 1961). In a survey in Scotland, Howie (1966) found that of 1,284 appendices removed 573 (45\%) were 'normal'. A similar study conducted inter-regionally in England and Wales would be needed to elucidate the problem furtheronly one example of the many questions HIPE can raise but not necessarily answer.

More importantly, however, HIPE has been able to demonstrate the large changes that have taken place in the pattern of admissions since 1949 (Table II). Although the 1949 data must be treated

TABLE II

SELECTED CAUSES OF ADMISSION TO NON-PSYCHIATRIC HOSPITALS IN ENGLAND AND WALES (THOUSANDS)

\begin{tabular}{|c|c|c|c|c|c|}
\hline Condition & & 1949 & 1959 & 1969 & 1970 \\
\hline $\begin{array}{l}\text { Respiratory tuberculosis } \\
\text { Lung cancer } \\
\text { Other cancers } \\
\text { (including blood) } \\
\text { Cerebrovascular accidents } \\
\text { Coronary heart disease } \\
\text { Bronchitis* } \\
\text { Tonsils and adenoids } \\
\text { Diseases of breast and } \\
\text { female genital organs } \\
\text { Hernia } \\
\text { Hyperplasia of prostate } \\
\text { Poisoning } \quad \text {... } \\
\text { Head injuries } \quad \text {. }\end{array}$ & \begin{tabular}{l|}
$\cdots$ \\
$\cdots$ \\
$\cdots$ \\
$\cdots$ \\
$\cdots$ \\
$\cdots$ \\
$\cdots$ \\
$\cdots$ \\
$\cdots$
\end{tabular} & $\begin{array}{r}51 \\
15 \\
120 \\
33 \\
14 \\
37 \\
106 \\
\text { N/A } \\
82 \\
23 \\
\text { N/A } \\
35\end{array}$ & $\begin{array}{r}46 \\
30 \\
159 \\
63 \\
56 \\
54 \\
192 \\
175 \\
105 \\
26 \\
21 \\
83\end{array}$ & $\begin{array}{r}18 \\
41 \\
218 \\
88 \\
113 \\
68 \\
134 \\
257 \\
122 \\
30 \\
90 \\
131\end{array}$ & $\begin{array}{r}17 \\
43 \\
230 \\
90 \\
117 \\
67 \\
116 \\
254 \\
118 \\
30 \\
93 \\
134\end{array}$ \\
\hline
\end{tabular}

* Some change in definition between 1949 and 1959. Source: HIPE (published and unpublished data) with extreme caution due to the selectivity of the 'sample', the consistency of trends is striking.

Other Aims OF HIPE

From the onset HIPE was also expected to be valuable in many other respects. MacKay (1951 specified that the data would assist in analysing occupancy in relation to diagnosis, in measuring trends in medical practice as they affect the need for hospital care, and for predicting future hospital load.

Taken together, these additional aims were the first indications that the information could also assist in the planning and distribution of resources and their effective management.

\section{Bed Use by Diagnosis}

There are variations in the utilization of nonpsychiatric beds between the sexes, between age groups, between geographical areas, and, of course, between diagnoses. Men have higher admission rates than women, but because there are more of them women use over $20 \%$ more beds than men, even when maternity admissions are excluded. The elderly are major users, with those aged 65 and over occupying $40 \%$ of the beds nationally (Ashley and Klein, 1971) and in the Birmingham region (Wall and Wharton, 1970). One bed in 11 contains a patient with cerebrovascular disease.

Further analysis of bed utilization by diagnosis highlights the effect of length of stay in determining that the needs for admission are effectively satisfied. In an area with a demonstrably higher level of illness more beds will not be required if lengths of stay are reduced by way of compensation. 
To return to the example of appendicitis, in 1969 Wales used $33 \%$ more beds for this condition than Wessex, an increment of about the same size as that of their admission rates, because both regions have almost identical average durations of stay $(8 \cdot 8$ and 8.9 days respectively). If, however, the average stay in Wessex was that of its neighbouring region, the South-west Metropolitan, where it was $9 \cdot 8$ days, the differential with Wales would have been reduced to $21 \%$. Conversely, if the stay in Wales had been that of Liverpool ( $9 \cdot 6$ days), it would have increased to $45 \%$. If Wales had performed as Liverpool and Wessex had performed as another neighbour, Oxford (with an avarage stay of 8.3 days), there would have been a $65 \%$ difference between them in bed use.

Thus clearly admission rates and length of stay play complementary roles in determining the magnitude of bed utilization.

\section{Trends in Medical Practice}

The measurement of trends in medical practice as the consequent predictive 'indicator' of future hospital load should be well within the scope of HIPE data both in terms of the changing pattern of case-mix and in the ever widening panoply of treatment. Ideally, it should identify the emergence of new syndromes, immediately indicate those conditions for which the need for hospital care is diminishing, and predict the future load from current innovations. That it is limited in the extent to which it achieves these admittedly high ideals is more often due to causes outside the system than within it; for example, the precision of the diagnostic information available to users is largely controlled by the relative rigidity of the International Classification of Diseases, the rate of revision of which is naturally geared to changes of opinion with regard to classification. These develop fairly slowly and concern mortality as well as morbidity.

Changes in trends warrant examination in more detail, particularly if they are sudden. Was the threefold increase in the one year from 1966 to 1967 in admissions for 'other diseases of bladder' (ICD 606) due to an artefact, changes in coding practice, changes in diagnostic criteria or an 'epidemic'? Each had to be eliminated in turn; in fact, changes in the coding of 'check cystoscopies' was largely responsible. That major changes can be caused by alterations in the pattern of treatment was demonstrated, for example, by Adelstein (1972) in drawing attention to the effect of the misuse of aerosol bronchodilators in asthma. Often the first indication of the extent of breakthroughs in treatment have come from sources other than recorded hospital

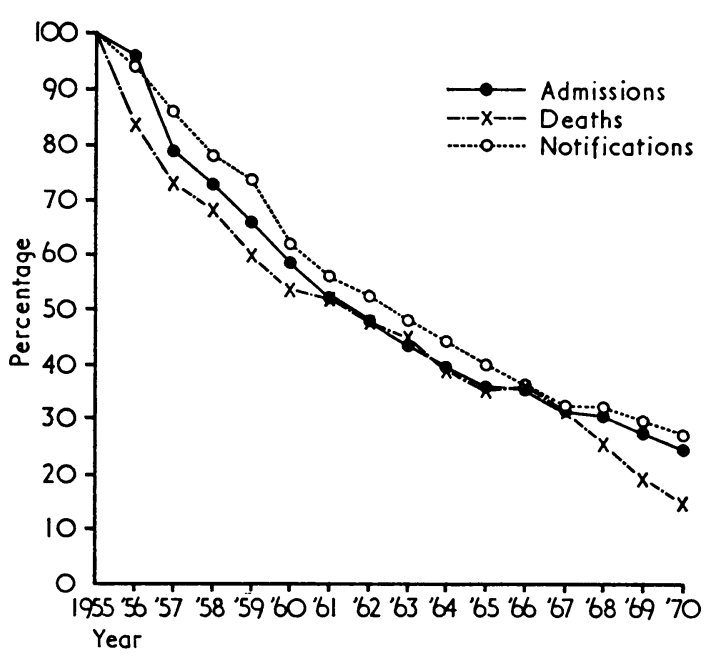

FIGURE-The fall of respiratory tuberculosis (1955 as base year). Sources: HIPE and Registrar General's Statistical Review, Part i (Tables) Medical.

admissions. For example, the reduction in admissions for respiratory tuberculosis succeeded the early fall in deaths following the introduction of 'triple therapy' but preceded the drop in notifications of the disease (Figure). After a period of coincident falls the pattern of these two other sources of data has recently diverged; but the trend in admissions seems to be following the notifications.

Nevertheless no other information can so accurately determine the extent of the continuing burden of this disease on the hospital service. It is at first surprising to find that cases of this now apparently comparatively rare condition discharged in 1968 had used more 'bed-days' $(3,757)$ than cases of hernia $(3,276)$, but because the figures are derived from retrospective usage direct comparisons are not possible.

Again, when changes occur in one of the principal diseases treated within a specialty, this may result in consequent changes in another. The fall in admissions for eczematous dermatoses due to the introduction of steroid therapy in the early sixties was also associated with an increased rise in admissions for psoriasis (Table III). Although this could have been the result of a similar increase in incidence of this condition or a new treatment, it is more likely that the relative rise in available dermatological beds, due to the release of those no longer required for the treatment of eczema, was the causative factor. Although there may be sound clinical reasons for the action, in this case it illustrates the general need for more introspection by clinicians into their real needs, as distinct from using what they have. 
TABLE III

TRENDS IN DERMATOLOGICAL ADMISSIONS, ENGLAND AND WALES

\begin{tabular}{c|c|c|c|c}
\hline \multirow{2}{*}{ Year } & \multirow{2}{*}{$\begin{array}{c}\text { Dermatology } \\
\text { Beds Occupied } \\
\text { (daily average) }\end{array}$} & \multicolumn{3}{|c}{ Annual Admissions } \\
\cline { 5 - 6 } & & $\begin{array}{c}\text { All } \\
\text { Dermatology }\end{array}$ & Eczema & Psoriasis \\
\hline 1958 & 1,762 & 21,084 & 11,390 & 3,620 \\
1959 & 1,759 & 21,858 & 11,210 & 3,870 \\
1960 & 1,786 & 22,214 & 11,050 & 4,230 \\
1961 & 1,721 & 21,975 & 11,510 & 4,370 \\
1962 & 1,654 & 21,777 & 9,740 & 4,520 \\
1963 & 1,603 & 22,053 & 8,850 & 5,200 \\
1964 & 1,602 & 22,314 & 8,660 & 5,560 \\
1965 & 1,617 & 21,998 & 7,870 & 6,470 \\
1966 & 1,612 & 23,012 & 7,990 & 6,460 \\
1967 & 1,604 & 23,410 & 7,920 & 6,870 \\
\hline
\end{tabular}

Sources: Annual reports of DHSS (from Forms SH3) and HIPE (published data).

\section{The Use of HiPE in Planning}

HIPE has rarely been used regionally in planning the scale and distribution of resources, in particular the need for beds. There were theoretical and practical reasons for this. The information only represents a measure of past use, and in a situation of apparent unmet demand, as manifested in waiting lists for admission, let alone unmet need, itappeared that future provision should in some way allow for this.

Despite this limitation, in one instance at least (Ramsay, 1965) it was used to show how and to what extent planning using the traditional bed norms needs to be modified. Ramsay's studies, relating to the East London area of the North-east Metropolitan Region, showed local variation in admission rates and bed use with specifically a greater preponderance of bronchitis than in the rest of the region. These studies also enumerated the extent to which boroughs 'imported or exported' patients according to the extent and type of service provided, and concluded that flexibility in planning was needed. At that time HIPE was the only vehicle available to determine at least a possible 'coefficient of expansion' for any area.

The Department of Health and Social Security does, however, make intensive use of the data for administrative and planning purposes. One example is the measurement of flows of patients across regional board boundaries and to teaching hospitals in connection with the allocation of finance. Another example was the use of HIPE in the study of maternity bed needs for the Peel report (Department of Health and Social Security, 1970).

\section{The Annual Hospital Return}

The delay in the availability of HIPE, already noted, has meant that the data from the Annual Hospital Returns (Form SH3) have usually been preferred for planning purposes, because although coarser in nature they had the advantage of being more up to date. They are traditionally obtained from daily ward returns, although recently other sources have been used experimentally. They are the only source of information on hospital use which has been continually and comparably available for all National Health Service hospitals since the beginning of the NHS. National and some regional summaries are published in the Annual Reports of the Department of Health, the Annual Digest of Health Statistics, and elsewhere.

The value of $\mathrm{SH} 3$ information cannot be dismissed, but its restriction to departments (specialties) limits its usefulness. For each of these departments it basically records available and occupied beds, discharges and deaths, mean duration of stay, and waiting lists. Throughput (average number of discharges per bed per year) has been added since 1970 , although the calculation has always been possible from the data provided, as has that of bed occupancy rates. It is also still the only regular source of basic out-patient data.

Figures from the $\mathrm{SH} 3$ are also used to estimate the completeness of the HIPE $10 \%$ sample. In 8 crude terms this is the best method available but there are some differences in definition between the two sources. For example, transfers between departments and the recording of spells in preconvalescent beds are treated differently. For a full description of the definitions used on Form SH3, some of which have varied slightly over time, the notes for guidance issued by the Department of Health and Social Security annually should be consulted.

\section{Hospital Activity Analysis}

If the drawbacks already discussed made HIPE an unsuitable tool for long-term planning, it was deemed to be even less appropriate for shorter term management. There was felt to be a need for a system of in-patient information with a capability of feedback to provide each hospital consultant with details of the performance of his own department.

Hospital Activity Analysis (HAA) was initiated (Benjamin, 1965) with this aim principally in view. The information to be recorded was not ambitious, being for the most part identical with that already collected for HIPE, although it was envisaged that the facility for additional items should be built in from the start. The scale of data collection $(100 \%$ discharges from all hospitals) and the insistence on rapid feedback with regional data processing and 
TABLE IV

PARTICIPATION IN HOSPITAL ACTIVITY ANALYSIS (SEPTEMBER 1971)

\begin{tabular}{|c|c|c|c|c|c|c|c|}
\hline \multirow{2}{*}{\multicolumn{2}{|c|}{ Type of Hospital }} & \multicolumn{3}{|c|}{ Hospitals } & \multicolumn{3}{|c|}{ Deaths and Discharges } \\
\hline & & \multirow{2}{*}{$\begin{array}{r}\text { Total } \\
1,750 \\
84 \\
43\end{array}$} & \multicolumn{2}{|c|}{ No. ${ }_{\text {participating }} \%$} & \multirow{2}{*}{$\begin{array}{c}\text { Total } \\
3,740,529 \\
370,552 \\
274,835\end{array}$} & \multicolumn{2}{|c|}{ No. included } \\
\hline $\begin{array}{l}\text { Regional Board } \ldots \\
\text { London teaching ... } \\
\text { Provincial teaching }\end{array}$ & $\begin{array}{l}\cdots \\
\cdots \\
\cdots\end{array}$ & & $\begin{array}{r}1,221 \\
27 \\
30\end{array}$ & $\begin{array}{l}69 \cdot 8 \\
32 \cdot 1 \\
69 \cdot 8\end{array}$ & & $\begin{array}{r}2,708,632 \\
113,398 \\
223,541\end{array}$ & $\begin{array}{l}72 \cdot 4 \\
30 \cdot 6 \\
81 \cdot 3\end{array}$ \\
\hline All & .. & 1,877 & 1,278 & $68 \cdot 1$ & $4,385,916$ & $3,045,571$ & $69 \cdot 4$ \\
\hline
\end{tabular}

Source: DHSS Personal communication.

analysis were, however, innovations. The introduction of computers into the health service, however, made these aims feasible (Dodman and Eastham, 1965) and also made possible the transfer of a $10 \%$ sample to the General Register Office to form the basis of HIPE and so prevent double data collection.

The regions and their constituent hospitals started to introduce the system with varying degrees of enthusiasm and in all but a few the build-up has been prolonged. Now most, if sadly not all, regions have conquered the inevitable teething troubles and the data are beginning to flow (Table IV), although more slowly in London teaching hospitals than elsewhere.

At present most regions do not collect HAA data in respect of psychiatric or maternity patients, although both may soon be included, for example, in Wessex (Alderson, 1972). In one hospital in the Sheffield region an experiment is proceeding in the collection of such data for out-patient attendances with encouraging results. Some regions are also developing methods for the compilation of routine bed statistics from HAA in-patient data.

\section{The Accuracy of Hospital Data}

Many appear satisfied with all three systems, but for others there are anxieties with regard to the accuracy of the data and the appropriateness of the output. Forsyth and Sheikh (1971), in reviewing the attitudes of 'cogwheel' committees to statistics of bed usage, observed that 'the accuracy and validity of the data are often questioned and their obvious shortcomings are pointed out as a reason for discarding them as a tool in medical management decisions'. Additionally, others who accept the information find difficulty in translating it into the appropriate management action.

Of course the accuracy of the information is of concern to all users and potential users. Because of the similarity in composition the standard of accuracy of HAA is probably in many respects similar to that of HIPE on which, however, there has been as yet no comprehensive validation study. This is unsatisfactory but understandable considering the magnitude of the operation. Validation also implies the existence of standards against which comparisons can be made. For the diagnostic data-the most sensitive to variations in local practice-comparative standards that are available are complex and restricted to individual conditions. HIPE data are, of course, extensively 'cleaned to remedy incredible associations' (Wilson, 1970) but this does raise the question of how many other not so obvious errors are present but remain concealed because they do not appear exceptional or inconsistent.

Our present evidence is fragmentary and conflicting and most of it is obtained from The Scottish Hospital In-Patient Statistics (SHIPS), the sister enquiry in Scotland, which has been fully described by Heasman (1968, 1970a).

\section{Demographic Data}

An extensive study on the statistics by Lockwood (1971) drew a sample of 2,515 forms from 38 hospitals randomly selected from the 90 such hospitals with more than 100 beds. The information on each form was compared with that available in the patient's medical care record. Out of nine items of demographic data examined by Lockwood only two were less than $95 \%$ correct, these being area of residence $(94.8 \%)$ and occupation $(83.6 \%)$. The latter item of information is at present not routinely collected in England and Wales, having been discontinued because of poor reporting; it is, however, obtained for HAA in some regions. Area of residence is a different matter and is a crucial item when producing population based statistics. Here Lockwood's data are at variance with those of the more elaborate study, also in Scotland, of Gruer (1970), who found much larger error rates.

In 1961 the then General Register Office first warned that admission rates in urban districts 
which have the same name as the surrounding rural districts may be artificially raised for this reason (HIPE for 1958). In 1967, however, after attempting to estimate the extent of erroneous recording of persons living in rural areas as urban dwellers, the GRO concluded that it seemed doubtful whether this type of error is of much practical importance (HIPE Commentary for 1960 and 1961). Gruer, after examining the coding of addresses in rural civil parishes in Scotland, again drew attention to this problem by highlighting the difficulties and effects of assigning postal addresses to administrative areas. Of addresses of patients treated in one hospital which she investigated, over $90 \%$ from civil parishes that are not main postal addresses were incorrectly coded to parishes that are main postal addresses. Although some $10 \%$ of records of patients from parishes that are main postal addresses were also misclassified, these were allocated to other main postal address parishes. City addresses were not so affected.

By examining the discharge rates of all the civil parishes in Scotland, Gruer concluded that the rate for those that are main postal addresses was significantly higher than that for parishes which are not main postal addresses, and she postulated that similar coding errors may be occurring at rural and urban district level in England and Wales.

Certainly in one region, East Anglia, the highest admission rates are in small urban areas that are also post towns (Table V). Conversely, the lowest rates are in similar sized towns not so designated. In at least some of the areas with the highest rates the Post Office serves areas 'over the boundary' where addresses do not contain the intermediate name of a village and thus are quite possibly miscoded. Whether, however, the same situation occurs as in Scotland remains to be determined.

Gruer suggested that the remedy for this situation may lie in the system of postal codes now covering large sections of the country. This will undoubtedly eliminate some of the present difficulties of coding but it will then be essential to have data relating to the population served in the area of any such code and this is not yet available.

\section{Administrative and Diagnostic Data}

Lockwood (1971) found that any errors that occurred in the principal items of administrative information relating to specialty, length of stay, source of admission, and mode of discharge were of minor significance. In HIPE the erroneous recording of 'death' in only about $0.05 \%$ of records is usually of little statistical importance (Wilson, 1970) but has been shown to affect the case fatality rate for a condition of low mortality, as in the case of tonsillectomy (Ranger, 1968).

The accuracy of the diagnostic data is much more in question. Its overall validity depends on many factors, of which the completeness and standard of the clinical summaries are probably the most crucial as they often have to be abstracted by clerical staff with limited knowledge. The national introduction in 1970 of an abstract as an integral part of the standard record in line with a recommendation of the Tunbridge Committee (Ministry of Health, 1965) must have resulted in an improvement at the final stage of data extraction, but much still depends on the medical data on the identification sheet (HMR 1 I.P).

TABLE V

ADMISSION RATES, EAST ANGLIA, 1965-67

\begin{tabular}{|c|c|c|c|c|c|}
\hline Type of Area & $\begin{array}{c}\text { Contains } \\
\text { Post Town(s)† }\end{array}$ & $\begin{array}{c}\text { Population } \\
\text { Size }\end{array}$ & $\begin{array}{l}\text { No. of } \\
\text { Areas }\end{array}$ & $\begin{array}{c}\text { Total } \\
\text { Population }\end{array}$ & $\begin{array}{l}\text { Admission } \\
\text { Rate/1000 }\end{array}$ \\
\hline \multirow{3}{*}{$\begin{array}{c}\text { Urban } \\
\text { Districts* }\end{array}$} & No & Under 15,000 & 6 & 48,900 & $49 \cdot 8$ \\
\hline & Yes & $\begin{array}{c}\text { Under } 7,500 \\
7,500-14,999 \\
15,000 \text { and over }\end{array}$ & $\begin{array}{l}21 \\
11 \\
10\end{array}$ & $\begin{array}{r}90,040 \\
113,590 \\
594,540\end{array}$ & $\begin{array}{l}91 \cdot 0 \\
85 \cdot 9 \\
80 \cdot 0\end{array}$ \\
\hline & All & All & 48 & 847,070 & $80 \cdot 2$ \\
\hline \multirow{3}{*}{$\begin{array}{c}\text { Rural } \\
\text { Districts }\end{array}$} & No & $\begin{array}{l}\text { Under } 15,000 \\
15,000 \text { and over }\end{array}$ & $\begin{array}{l}17 \\
22\end{array}$ & $\begin{array}{l}159,700 \\
546,940\end{array}$ & $\begin{array}{l}65 \cdot 7 \\
54 \cdot 7\end{array}$ \\
\hline & Yes & 15,000 and over & 5 & 101,940 & $54 \cdot 3$ \\
\hline & All & All & 44 & 808,580 & $56 \cdot 8$ \\
\hline Regional Total & & & 92 & $1,655,650$ & $68 \cdot 8$ \\
\hline
\end{tabular}

Source: HIPE (unpublished data)

* Including County Boroughs and Municipal Boroughs.

$\dagger$ A post town is the centre of a delivery area for mail and serves both the town itself and a variable surrounding area. 
That discharge notes may be far from complete has been demonstrated in the past (Nuffield Provincial Hospitals Trust, 1967), and Last (1970) has suggested that the efficiency of recording may be jeopardized 'because the most senior member of the clinical team is usually responsible for the decision to discharge a patient but the most junior member is responsible (commonly without adequate instruction or supervision) for compiling the case notes and for completing the medical details on the discharge summary'.

Despite these forebodings, Lockwood's evidence is of $94 \%$ accuracy as regards the transcribing and coding of the principal diagnosis. His picture is less happy for the second diagnosis $(66 \%$ accurate) or the third $(61 \%)$ due mainly to omissions. These diagnostic inaccuracies were not associated particularly with any specialty, age group or sex, and the error rate in the principal diagnosis was less than the $13 \%$ found by Alderson and Meade (1967) in their analysis of 105 hospital deaths reported to the Oxford Record Linkage Study, but deaths may be a special group in this respect.

Operations in Scotland were recorded with similar levels of accuracy; the principal operation was omitted or incorrect in $10 \%$ of cases and a second was omitted in a quarter of the records. Some specialties had noticeably high omission rates, usually for 'minor' procedures.

One does not know whether these findings can be replicated in England and Wales but, on the whole, misgivings about the overall general accuracy of the information obtained appear unfounded. Data from some groups of cases may, however, be more suspect. In particular, it is to be hoped that the standard of 'second diagnosis' information can be improved because at present its potential use in, for example, determining complication rates or for distinguishing between 'legitimately' and 'illegitimately' long durations of stay is impaired.

\section{SAMPLING}

Unlike HAA or SHIPS, HIPE data are also subject to sampling variation, errors, and deficiencies. A $10 \%$ sample is expected, but for the latest years published only about $9 \%$ was actually received. Despite the fact that there are marked differences between departments it is usually assumed that shortages are principally due to random failure of hospitals to supply data. Bennett (1966) found, for example, that the deficiencies in the sample from one London teaching hospital were concentrated in certain months when they might have been due to staff sickness, holidays or
TABLE VI

ACCURACY OF HIPE SAMPLING IN ONE GENERAL HOSPITAL, 1966

\begin{tabular}{lc|c|c|c}
\hline \multicolumn{1}{c|}{ Specialty } & $\begin{array}{c}\text { No. of Forms } \\
\text { in Sample }\end{array}$ & $\begin{array}{c}\text { No. of } \\
\text { Discharges* }\end{array}$ & $\begin{array}{c}\text { Percentage } \\
\text { Sample }\end{array}$ \\
\hline General medicine & $\ldots$ & 41 & 1,312 & $3 \cdot 1$ \\
Dermatology &. & 3 & 102 & $2 \cdot 9$ \\
General surgery & $\ldots$ & 90 & 2,798 & $3 \cdot 2$ \\
and urology & $\ldots$ & 80 & 1,167 & $6 \cdot 9$ \\
ENT & $\ldots$ & 30 & 1,064 & $2 \cdot 8$ \\
Orthopaedics & $\ldots$ & 26 & 448 & $5 \cdot 8$ \\
Ophthalmology & $\ldots$ & 3 & 137 & $2 \cdot 2$ \\
Radiotherapy & $\ldots$ & 12 & 368 & $3 \cdot 3$ \\
Others &.. & 285 & 7,396 & $3 \cdot 9$ \\
All specialties &. & & & \\
\hline
\end{tabular}

* From Form SH3.

changes; and that in all other respects the sample was representative.

That this may not always be the case is illustrated in Table VI. In this general hospital a larger sample was supplied in respect of ENT and ophthalmology than the other specialties but whether this was due to recording over a longer period or to 'substitution' was not determined.

In another London teaching hospital Rosser (1972) has noted an $80 \%$ deficiency of deaths in the sample, and indeed in the example (Table VI) only $1 \%$ of deaths were reported to HIPE; but this is not the case nationally. Although until 1967 consistently about $5 \%$ less were reported than might be expected from death certificate information (Table VII), this latter source also includes private patients and deaths which occur in accident and emergency departments. Of the 15,000 deficiency each year at least 10,000 could be expected to be accounted for in these two ways, thus reducing unreporting to about $2 \%$. The reason for the change in the pattern since 1968 is so far obscure. However, the increasing number of large psychiatric units in non-psychiatric hospitals, which are excluded from HIPE but counted in death certification, could influence this, although such units are usually conceived primarily as short stay assessment units.

TABle VII

COMPARISON OF DEATHS IN NON-PSYCHIATRIC HOSPITALS REPORTED FROM TWO SOURCES

\begin{tabular}{c|c|c|c}
\hline Year & $\begin{array}{c}\text { Deaths in } \\
\text { Non-psychiatric } \\
\text { Hospitals* }\end{array}$ & $\begin{array}{c}\text { Estimated } \\
\text { Deaths Calculated } \\
\text { from HIPE† }\end{array}$ & $\begin{array}{c}\text { Proportion } \\
\text { Reported } \\
\%\end{array}$ \\
\hline 1962 & 253,505 & 239,240 & 94 \\
1963 & 262,321 & 249,220 & 95 \\
1964 & 255,375 & 239,280 & 94 \\
1965 & 263,045 & 224,700 & 93 \\
1966 & 271,535 & 258,990 & 95 \\
1967 & 266,104 & 249,500 & 94 \\
1968 & 288,318 & 262,600 & 91 \\
1969 & 293,340 & 269,910 & 92 \\
1970 & 295,309 & 263,400 & 89 \\
\hline
\end{tabular}

* Source: Registrar General's Statistical Review.

$\dagger$ Source: HIPE - calculated by application of year-specific multiplying factors. 


\section{Presentation}

Attractive and easily assimilated presentation can go a long way towards getting such data accepted as relevant and worth consideration. After some early experimentation HIPE has settled down to a relatively standard and now familiar output using a limited number of parameters. Recent Scottish data have been clearly presented (Lockwood, 1972) and have made extensive use of visual methods. HAA being conceived as more versatile also encourages the presentation of tabulations adjusted to local requirements or embodying extra factors which have been recorded. It is expected to be available to answer ad hoc enquiries as well as presenting statistics on a regular basis (Department of Health and Social Security, 1969a). These latter tabulations tend to follow the general pattern of HIPE although they are usually additionally subdivided according to individual hospitals and consultants. It has, however, been doubted (McNay, 1969) whether the routine production of detailed tabulations is economically worthwhile. Typically, a diagnostic index is also included; but this tends to be an extensive document and despite its inestimable value to research workers-particularly as a sampling frame for prospective studies-and its historical position as a source of information to consultants, it is now probably one of the major reasons why a 'clinical' diagnosis of 'computer diarrhoea' is often made on HAA.

In the early days, Robson (1967), as well as giving examples of these applications, also drew attention to the need for population based information at the local level. There is commendable national and regional use of the data in this form, and appropriate local population denominators are available. Both HIPE and HAA are regularly used to define catchment areas for individual hospitals and groups and to calculate the corresponding catchment populations. Alternatively, the data are available to relate hospital occurrences to already known populations.

The form of presentation is clearly of some importance if necessary clinical or administrative change is to follow. An appropriate summary of the data is the corner-stone at present, but the future probably lies in the foundations of two other methods. The first is to present the data diagrammatically, perhaps after the manner of Heasman and Carstairs (1971). Hopefully, with their epidemiological and statistical background, our future community physicians, whose functions will no doubt be to educate in this respect, will progressively adopt this approach.
Secondly, we must work towards the method of 'exception reporting', well known as a management tool in other fields where, as in health, there is a plethora of data. The stumbling block at present is the lack of a consensus as to the 'norms' to be used. This can and must be solved, even if the first step is to agree with each consultant his own personal values and to develop group or regional figures later. In a situation in which so much of the information that is forthcoming will relate to the large mass of routine work efficiently performed there is a need to do in other situations what has been done for maternal mortality by the confidential enquiry (Department of Health and Social Security, 1969b).

\section{USES OF THE STATISTICS}

Many of the varied uses of HIPE or HAA could be illustrated, but consideration of three specific aspects-admission rates, measures of performance, and indicators of outcome-will also demonstrate some of the difficulties and highlight some of the implications.

\section{Admission Rates}

Despite inaccuracies which have been described, examination of admission rates is crucial to the provision of hospital and community based services. In the early days these rates for any particular area appeared to be sacrosanct, with the general belief that they reflected local morbidity. Holland (1965), however, noted that, in the case of one of the major causes, respiratory disease, mortality and admission rates gave different indications of the distribution in England and Wales, the latter perhaps being affected by the number of available beds.

That the 'critical number method' when used for determining bed needs (Bailey, 1954, 1962; Nuffield Provincial Hospitals Trust, 1955) was usually found to reflect the number of beds presently available (Forsyth and Logan, 1960; Airth and Newell, 1962) was due in part to the acceptance that admission rates current at the time would continue. Although the method appears to be falling into disuse (Hindle, 1972) a variation of it was recently applied in a study of the needs of the elderly (Gedling and Newell, 1972).

This study also noted the usually insoluble problem of admission rates being considerably influenced by transfers between departments in the same hospital being recorded as one admission whereas interhospital transfers count as two.

It also drew further attention to inflation by readmission; in the elderly group which was specifically studied this amounted to about $1 \cdot 2$ admissions 
per patient. In comparison the Oxford Record Linkage study (Acheson and Barr, 1965) showed that $16.3 \%$ of patients were admitted more than once in a year, and recent evidence from Liverpool tends to confirm this. High admission rates may also be due to the presentation for treatment of previously unmet and perhaps unrecognized need, which view must, of course, carry some weight if the continued rise in national admission rates is to be justified but can equally reflect a lower 'threshold'.

By threshold is meant the criteria used for making admissions and, as Newell (1964) has observed, 'the supply of beds modifies demand in this respect. In an area with few beds the patients, practitioners and consultants are accustomed to few admissions and short durations of stay. In an area with many beds the threshold may be lower and cases who have passed over that threshold may be retained for longer than necessary'.

These criteria of threshold are often not applied consciously but are usually associated with the concept of severity, which cannot as yet be generally and comparatively measured. HIPE and SH3 data together, however, can illustrate levels of threshold, and Table VIII from these two sources compares regional surgical admission rates and surgical operations performed. The table demonstrates the range of operations to admissions and indicates that there are more admissions for investigation in some regions. This observation was confirmed from further HIPE data which showed that Liverpool, for example, with the lowest ratio used $2.4 \%$ of its surgical bed-days for investigatory procedures as against a national average of $1 \cdot 3 \%$.

\section{TABLE VIII}

SURGICAL ADMISSIONS AND OPERATIONS, 1967, PER 1,000 POPULATION

\begin{tabular}{|c|c|c|c|}
\hline Region* & $\begin{array}{l}\text { Admissions to } \\
\text { Surgical Beds } \dagger\end{array}$ & Operations $\ddagger$ & $\begin{array}{l}\text { Ratio \% } \\
\text { Operations: } \\
\text { Admissions }\end{array}$ \\
\hline 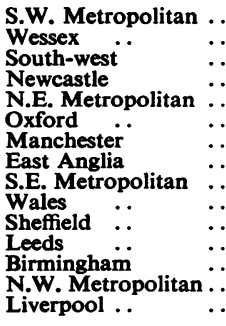 & $\begin{array}{l}50 \cdot 7 \\
46 \cdot 5 \\
43 \cdot 9 \\
49 \cdot 9 \\
53 \cdot 2 \\
52 \cdot 6 \\
51 \cdot 3 \\
40 \cdot 2 \\
52 \cdot 1 \\
49 \cdot 6 \\
40 \cdot 0 \\
51 \cdot 7 \\
44 \cdot 5 \\
58 \cdot 9 \\
57 \cdot 9\end{array}$ & $\begin{array}{l}42 \cdot 9 \\
38 \cdot 8 \\
36 \cdot 5 \\
40 \cdot 3 \\
42 \cdot 3 \\
41 \cdot 3 \\
39 \cdot 3 \\
30 \cdot 6 \\
39 \cdot 2 \\
37 \cdot 3 \\
29 \cdot 9 \\
36 \cdot 1 \\
31 \cdot 9 \\
41 \cdot 5 \\
39 \cdot 5\end{array}$ & $\begin{array}{l}85 \\
83 \\
83 \\
81 \\
80 \\
79 \\
77 \\
76 \\
75 \\
75 \\
75 \\
74 \\
72 \\
70 \\
68\end{array}$ \\
\hline England and Wales .. & $49 \cdot 5$ & $37 \cdot 1$ & 76 \\
\hline
\end{tabular}

- Including the appropriate teaching hospitals.

Sources: † Forms SH3.

‡ HIPE-including non-operative surgical procedures.

\section{Measures of Performance}

Effective management of the health services includes a continuing capacity to monitor the results of decisions taken (Logan, Klein, and Ashley, 1971), and this implies suitable measures of performance. Most measures used at present are traditional, and foremost is length of stay for the very good reason that reductions in it produce great economic saving.

Comparisons of durations of stay are usually by examination of the arithmetic mean or median, both of which are appropriate in conditions such as elective surgery in which distributions are not markedly skewed. Wilson (1970), however, in advocating the geometrical mean, observes that it is distributed more symmetrically and its standard error can be used with greater security, but nonstatisticians do not appreciate these virtues'.

Undoubtedly, however, the demonstration of often subtle differences demanding appropriate action are achieved only by presentation of the entire distribution, particularly when hospitals are being compared because some exhibit definite bimodal patterns (Heasman, 1964). HIPE routinely includes details on the national distribution of stay, and in Scotland 'quartiles' of their length of stay distribution are presented to individual consultants (Heasman, 1970b).

The underlying reasons and their solution may need considerable investigation, but the data may provide pointers. Clearly a long 'tail' to the distribution may indicate the blocking of beds by 'chronic' cases whereas a bimodal distribution can be caused by insufficient out-patient investigation, inadequate operating theatre time or a non-optimal admissions policy. Many of these problems can be tackled with operational research techniques where again the data may be helpful. For example, Luck, Luckman, Smith, and Stringer (1971) used the arrival patterns of emergency admissions in simulation models in order to determine, in conjunction with survey data, such an optimal admission policy for waiting list cases.

Bennett (1970) has pointed out that superficial comparisons can be highly deceptive because they do not take all relevant factors into account. He, for instance, drew attention to the generally longer hospital stays experienced by the non-married (single, widowed, and divorced), and, as Kramer (1969) has observed, 'the patterns of life of this group must be taken into account in planning and evaluating hospital services'.

Throughput, occupancy rates, and waiting lists are also valuable indicators of the intensity of 
TABLE IX

RANGE OF THROUGHPUTS IN GENERAL MEDICAL BEDS IN A REGION, 1968

(Admissions per bed per year)

\begin{tabular}{lc|c|c|c}
\hline $\begin{array}{c}\text { Throughput } \\
\text { Range }\end{array}$ & $\begin{array}{c}\text { No. of } \\
\text { Hospitals }\end{array}$ & $\begin{array}{c}\text { Total No. of } \\
\text { Available Beds }\end{array}$ & $\begin{array}{c}\text { Average No. of } \\
\text { Beds/Hospital }\end{array}$ \\
\cline { 1 - 1 } Under 10 &. & 4 & 402 & 100 \\
$10-14$ & $\cdots$ & 7 & 461 & 66 \\
$15-19$ & $\cdots$ & 6 & 777 & 127 \\
$20-24$ &. & 8 & 562 & 70 \\
25 and over &. & 2 & 80 & 40 \\
All &. & 27 & 2282 & \\
\hline
\end{tabular}

performance. However, Williams (1968) has indicated that occupancy and waiting lists in particular are subject to misinterpretation; and Baldwin (1968) pointed out that, because of a number of factors, a wide range of occupancy rates may occur in units which are able to cope effectively when there is neither unmet demand nor under-utilization.

Equally, throughput as a measure of hospital department or individual consultant performance is often extensively modified by differences in case-mix. Although some specialties are affected more than others, seemingly similar departments appear to function at markedly dissimilar rates. Table IX shows the considerable range of throughputs for departments of general medicine demonstrated in one region. In this particular case there was a larger proportion of low turnover beds than in other regions which seemed to be attributable to an excess of general medical beds substituting for a deficiency of geriatric beds.

\section{OUTCOME}

Despite the fact that only the very basic data on treatment and outcome are currently collected, one series of indicators available is operation rates. In Scotland, for example, only three-quarters of consultants operate on more than $90 \%$ of their cases of hernia; and $10 \%$ of consultants operate on less than $80 \%$ of such cases (Heasman and Carstairs, 1971), but the reasons for such apparent differences in action in this condition are obscure.

Similarly, another series of indicators that can be determined is mortality rates or, more strictly spell-fatality rates since the denominator is 'discharges' and not 'persons'. Even these two rather crude indicators taken together may, however, be of some considerable significance. Differences in 'case-fatality rates', for many common conditions, between teaching and Regional Board hospitals are now of long standing (Lee, Morrison, and Morris, 1957; Lipworth, Lee, and Morris, 1963).

For one condition, hyperplasia of prostate, these differences have been shown to be related to the load of emergency admissions and to variations in operation rates (Ashley, Howlett, and Morris, 1971). But to do this study required a special survey and the results could not be confirmed in the HIPE data primarily because of their deficiencies and limitations.

\section{Future DevelopMent}

The data are at present limited by the restrictions of the system and shortcomings in the extraction together with deficiencies in the recording in the basic information-the hospital medical record.

For the future we need to overcome these limitations, enlarge the data set with additional medical and social indicators, and work towards a total integrated information system.

The principal restriction of the system is, of course, that the information is event rather than person orientated, and this severely limits its applications, for example, in clinical epidemiology. Although the only satisfactory method of overcoming this lies in the adoption of record linkage more extensively, much could be done by simple but standard categorization of admissions-for example, to allow preliminary investigatory admis sions, or secondary admissions for complications to be easily segregated.

Clearly, shortcomings in the extraction of the data are not as serious as many have feared. Nevertheless, there is still room for improvement, particularly on the diagnostic side. Equally, however, the need for more uniform and accurate recording of occupation and more detailed residence data is an urgent requirement, particularly for research purposes.

There is a dearth of suitable measures of severity and outcome. The development of these combined with suitable standard definitions of such concepts as 'complications' and 'disability' will enable the effectiveness of the services provided to be more readily determined. But part of the problem undoubtedly lies with 'errors of omission, rather than commission' in the hospital medical records. These cannot be easily rectified without a greater awareness on the part of those compiling these records of the ultimate consequences of their actions. A general improvement to what is an acceptably uniform standard is only a start; Gordon (1970), for instance, advocates the acceptance by clinicians that they should increasingly record the reasons behind clinical decisions that are taken.

The need for more indicators of social condition is self-evident when there is a varied pattern of use by social class in hospital (Carstairs, 1966) although 
in the community low use and low social class seem more uniformly related (Alderson, 1970). Categorization by social class must, however, conceal as many differences as it reveals, and there seems to be a good case for including at least information about ethnic origin and housing tenure.

Management is also currently limited by the scope of information on other parameters of use, but the extent to which the data set can be enlarged is constrained by the availability of appropriate measures and by the balance between the cost of the collection of those that do exist and the benefit gained. Superficially, however, it appears illogical to record elsewhere information on the use made of such services as pathology or radiology without relating them to individuals, which would allow some prediction of the future demands on these services based on the expected case mix (Ashley, Pasker, and Beresford, 1972). Equally, when measures of nursing dependency are available and recorded in some hospitals (Barr and Moores, in preparation), their combination with demographic and diagnostic data would enhance the value of all three.

The difficulties in adding this kind of continuous or semicontinuous data to the system in its present form, however, seems to stem from an inability to identify the minimum part of the wealth of potential data which will give the optimal benefit.

The long-term objective is a fully automated total hospital intelligence system, and this will permit compilation not only of all the present data but also those on symptomatology and therapy. Many of the difficulties of the classification of these additional data are being painstakingly unravelled at present. Unless, however, all collected data are retained, as Collen (1970) for instance implies, then to avoid subsequent massive problems of storage and retrieval considerable condensation will still be necessary. Thus the need to develop suitable summaries of the data is not just a temporary academic exercise.

Hospital data seem to have achieved most of the somewhat limited objectives with which the various systems were conceived. In general, the data are valid but all the potential uses have not been explored nor has data analysis gained universal acceptance as a management tool.

The major reason for this state of affairs probably lies in the inability of such information as at present derived to solve either research or management problems. Nevertheless it is quite capable of identifying problem areas for further study and thus it is of immediate use to administrator, manager, and researcher alike.

\section{OUTLINE}

The presently available sources of hospital inpatient data and the statistics derived from them are reviewed and their status as measures of total or comparative morbidity is considered. The additional aims and limitations of such data when used for the planning of services and other management purposes are outlined. The current evidence regarding the validity of the data is also evaluated. Finally, possible changes and additions which might be incorporated in order to enhance the information and increase its benefit to a future totally integrated intelligence system are suggested.

I am grateful to my colleagues in the Medical Statistics Division of the Office of Population, Censuses, and Surveys, in particular Dr. P. Lambert and Dr. W. A. Wilson, and in the Statistics Division of the Department of Health and Social Security, in particular Mr. D. Evans and Mrs. S. Keith, for valuable assistance and advice. I should also like to acknowledge the ready help and encouragement of many colleagues in the Department of Public Health of the London School of Hygiene and Tropical Medicine during the preparation of this paper.

\section{REFERENCES}

ACHeson, E. D., and BARR, A. (1965). Multiple spells of in-patient treatment in a calendar year. Brit. J. prev. soc. Med., 19, 182.

Adelstein, A. M. (1972). The medical division of the Office of Population, Censuses and Surveys-objectives and methods. Health Trends, 4, 2.

AIRTH, A. D., and Newell, D. J. (1962). The demand for hospital beds. University of Durham, Newcastleupon-Tyne.

Alderson, M. R. (1970). Social class and the health service. Med. Offr, 124, 50.

(1972). The Wessex Plan for computing. In: Spectrum, 71, edited by M. E. Abrams, p. 141. Butterworth, London.

-, and MeADE, T. W. (1967). Accuracy of diagnosis on death certificates compared with that in hospital records. Brit. J. prev. soc. Med., 21, 22.

Ashley, J. S. A., Howlett, A., and Morris, J. N. (1971). Case-fatality of hyperplasia of the prostate in two teaching and three regional-board hospitals. Lancet, 2, 1308.

- and KLeIN, R. E. (1971). The challenge of another million by 1991. Mod. Geriat., 1, 310.

- Pasker, P., and Beresford, J. C. (1972). How much clinical investigation? Lancet, 1, 890.

BaILEY, N. T. J. (1954). Queueing for medical care. Appl. Statist., 3, 137.

- (1962). Calculating the scale of inpatient accommodation. In: Towards a Measure of Medical Care. (Nuffield Provincial Hospitals Trust). Oxford University Press, London. 
Baldwin, J. A. (1968). How many beds? A critical discussion of some approaches to hospital planning I. General hospitals. Hlth Bull. (Edinb.), 26, No. 2, 25.

BARR, A., and MoOREs, B. Establishing the establishment. (In preparation).

Benjamin, B. (1965). Hospital activity analysis: an information feedback for the consultant. Hospital (Lond.), 61, 221.

Bennetr, A. E. (1966). Case selection in a London teaching hospital. Med. Care, (Lond.), 4, 138.

(1970). Sources of data. In: Resources in Medicine, edited by J. Collins, p. 17. King Edward's Hospital Fund, London.

Carstairs, V. (1966). Distribution of hospital patients by social class. Hlth Bull. (Edinb.), 24, No. 3, 59.

ColLEN, M. F. (1970). General requirements for a medical information system (MIS). In: Proceedings of a Conference on Medical Information Systems, p. 1. United States Department of Health Education and Welfare, Washington.

Department of Health and Social Security (1969a). National Health Service, Hospital Activity Analysis, H.M. (69) 79.

(1969b). Report on confidential enquiries into maternal deaths in England and Wales 1964-1966. Reports on Public Health and Medical Subjects No. 119. H.M.S.O., London.

Welsh Office (1970). Domiciliary Midwifery and Maternity Bed Needs. (Central Health Services Council) H.M.S.O., London.

(1971). National Health Service Reorganisation. Consultative Document. London.

- and Office of Population, Censuses and SURVEYS (1972a). Report on Hospital In-Patient Enquiry for the year 1968. H.M.S.O., London.

- , and - (1972b). Report on Hospital In-Patient Enquiry for the year 1969. H.M.S.O., London.

Dodman, A., and Eastham, C. (1965). Hospital activity analysis: an enquiry into the automated collection of data. Hospital (Lond.), 61, 622.

Forsyth, G., and LogAN, R. F. L. (1960). The Demand for Medical Care. Oxford University Press, London.

- , and SHEIKH, J. M. (1971). The mechanics of medical management. In: In Low Gear?, edited by G. McLachlan, p 1. Oxford University Press, London.

Gedling, P., and Newell, D. J. (1972). Hospital beds for the elderly. In: Problems and Progress in Medical Care-Seventh Series, edited by G. McLachlan, p. 131. Oxford University Press, London.

GoRDon, B. L. (1970). Terminology and content of the medical record. In: Proceedings of a Conference on Medical Information Systems, p. 53. United States Department of Health, Education and Welfare, Washington.

Gruer, R. (1970). Hospital discharges in relation to area of residence. Brit. J. prev. soc. Med., 24, 124.
Halevi, H. S. (1969). Patterns of hospitalization in England and Israel. Brit. J. prev. soc. Med., 23, 196.

Heasman, M. A. (1964). How long in hospital? Lancet, $\stackrel{\mathbb{Q}}{?}$

2, 539. sources and uses. Hlth Bull. (Edinb.), 26, No. 4., 10. 맘 (1970a). Scottish hospital in-patient statistics. In: 을

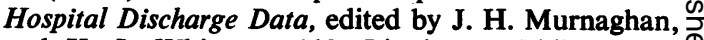
and K. L. White, p. 113. Lippincott, Philadelphia. $\stackrel{\mathbb{Q}}{\Omega}$ (Suppl. to Med. Care (Philad.), 8, No. 4). statistics (SCRIPS). Scot. med. J., 15, 386.

, and CARSTAIRS, V. (1971). Inpatient management: $\overrightarrow{\vec{\omega}}$ variations in some aspects of practice in Scotland Brit. med. J., 1, 495.

HiNDLE, A. (1972). Operational research in the health $\stackrel{\rho}{\stackrel{\rho}{\rho}}$ service. In: The Health Services-Administration of Research and Management, edited by H. P. Ferrer, p. 149. Butterworth, London.

Holland, W. W. (1965). The rationale of field surveys of Milbank mem. Fd. Quart., 43, No. 2. pt. 2, p. 77.

HowIE, J. G. R. (1966). Death from appendicitis and $\vec{D}$ appendicectomy. Lancet, 2, 1334.

KRAMER, M. (1969). Statistics of mental disorders in the $\frac{\bar{c}}{\omega}$ United States: current status, some urgent needs and $\overrightarrow{\vec{\theta}}$ suggested solutions. J. roy. statist. Soc., Ser. A, 132, 358.

LAST, J. M. (1970). Data collection requirements patient management. In: Hospital Discharge Da' edited by J. Murnaghan, and K. L. White, p. 159. Lippincott, Philadelphia. (Suppl. to Med.Care (Philad.), 8, No. 4).

LEE, J. A. H. (1961). "Appendicitis" in young women. $\stackrel{\circ}{\stackrel{\circ}{\perp}}$ Lancet, 2, 815.

-, Morrison, S. L., and MorRIS, J. N. (1957). $\frac{\mathrm{O}}{3}$ Fatality from three common surgical conditions in teaching and non-teaching hospitals. Lancet, 2, 785.

Lichtner, S., and Pflanz, M. (1971). Appendectomy in the Federal Republic of Germany: epidemiology and medical care patterns. Med. Care, (Philad.), 9, 311 .

Lipworth, L., LeE, J. A. H., and MorRis, J. N. (1963). Case-fatality in teaching and non-teaching hospitals. 1956-59. Med. Care, (Philad.), 1, 71.

Lockwood, E. (1971). Accuracy of Scottish hospital 0 morbidity data. Brit. J. prev. soc. Med., 25, 76.

(1972). Scottish hospital morbidity data 1961-1968. 은 Scottish Health Service Studies, No. 20. Scottish Home and Health Department, Edinburgh.

Logan, R. F. L., Klein, R. E., and Ashley, J. S. A. N (1971). Effective management of health. Brit. med. J., N 2, 519.

LUCK, G. M., LuCKMAN, J., SMith, B. W., and STRINGER, J. (1971). Patients, Hospitals and Operational Research. Tavistock Publications, London.

MACKAY, D. (1951). Hospital morbidity statistics. Studies on Medical and Population Subjects, No. 4. General Register Office, London. 
MCNAY, R. A. (1969). Hospital activity analysis: experience in the area of the Newcastle Regional Hospital Board. Hospital (Lond.), 65, 308.

Ministry of Health (1965). The Standardisation of Hospital Medical Records. H.M.S.O., London.

- (1967). First Report of the Joint Working Party on the Organisation of Medical Work in Hospitals. (Chairman: Sir George Godber). H.M.S.O., London.

Morris, J. N. (1957). Uses of Epidemiology, p. 40. Livingstone, Edinburgh.

Newell, D. J. (1964). Problems in estimating the demand for hospital beds. J. chron. Dis., 17, 749.

Nuffield Provincial Hospitals Trust (1955). Studies in the Function and Design of Hospitals. Oxford University Press, London.

(1967). The Flow of Medical Information in Hospitals. Oxford University Press, London.

Ramsay, T. A. (1965). New district hospitals. Problems associated with assessing the need and the facilities required. Hospital (Lond.), 61, 345.

RANGER, D. (1968). Tonsillectomy and adenoidectomy. Lancet, 1, 1379.
Robson, D. M. (1967). Hospital activity analysis: its use in hospital management. Hospital (Lond.), 63, 388.

Rosser, R. (1972). Discrepancies in hospital data. Lancet, 1, 1070.

UemurA, K. (1970). Collection of data from established sources. In: Data Handling in Epidemiology, edited by W. W. Holland, p. 55. Oxford University Press, London.

Wall, M., and Wharton, D. A. (1970). The elderly in hospital: a survey of patients age 65 and over in nonpsychiatric hospitals in 1968. Hospital (Lond.), 66, 414.

Williams, B. (1968). The use and misuse of bed-occupancy and waiting-list figures. Lancet, 1, 1029.

Wilson, W. A. (1970). Hospital in-patient enquiry for England and Wales. In: Hospital Discharge Data. edited by J. Murnaghan, and K. L. White, p. 98. Lippincott, Philadelphia. (Suppl. to Med.Care (Philad.), 8, No. 4.

World Health Organisation (1968). Morbidity Statistics. Twelfth Report of the Expert Committee on Health Statistics. Technical Report Series No. 389, Geneva. 